\title{
Research on Energy Flow Optimization of Compound Storage System in Pure Electric Vehicle with Longitudinal Dynamics
}

\author{
Meng Dawei, Zhang Yu, Zhou Meilan and Tian Xiaochen \\ Department of Electrical Engineering, Harbin University Of Science And Technology \\ , Harbin 150080 \\ zhangyu8419@163.com
}

\begin{abstract}
Aiming at short endurance mileage for electric vehicle, effected vehicle life because of battery excessive charging and discharging, the control method is put forward making use of super-capacitor to recovery regenerative braking energy, Hafei-Saibao electric vehicle is as example, seven kinds of topology with composite energy-single load are researched on power consumption, and the force condition of front and rear wheels is analyzed for front driving vehicle, the required energy of front wheel is detected to develop control strategy. On the basis of experimental data, co-simulation is achieved in the vehicle special simulation software, the experimental results show endurance mileage of improved car has increased by $34 \%$, endurance mileage after being charged is 243 kilometer, the per hundred kilometers consumption has been decreased to $7.5 \mathrm{~kW}$.h from $12 \mathrm{~kW} . \mathrm{h}$, the electrical consumption has been decreased by $37.5 \%$, and the full load characteristics is optimized.
\end{abstract}

Keywords: Compound storage system Energy flow longitudinal dynamics pure electric vehicle

\section{Introduction}

The huge energy consumption and serious pollution of the environment are the inevitable problems in our country. By 2012, the amount of gasoline used to drive the car consumption has accounted for $90 \%$ of the total gasoline use in China. Facing the global warming problems of environmental deterioration, Chinese government has made a formal commitment to the global: by 2020, carbon dioxide emissions caused by per unit of GDP creation reduced by $40 \% \sim 45 \%$ than in 2005 , vehicle manufacturers must depend on technical innovation, electrical vehicle arises at the historic moment.

\section{Basic Parameter Matching for Vehicle}

Parameter matching is on the basis of original Hafei Saibao electric vehicle, the basic parameters of the vehicle are shown in Table 1. The rated power of motor $P_{N}$ is determined according to the expected maximum speed of the vehicle; the maximum instantaneous power $P_{N 1}$ is determined according to the biggest climbing angle when the car is climbing; the maximum output power $P_{N 2}$ is determined according to the last moment in the acceleration of the vehicle. So the choice of the motor peak power is $P_{\max } \geq \max \left\{P_{N}, P_{N 1}, P_{N 2}\right\}$, as shown in the following equations. At last the maximum power of the selected motor is $98.5 \mathrm{~kW}$, the output power is $60 \mathrm{KW}$, maximum torque is $300 \mathrm{~N} . \mathrm{m}$. 


$$
\left\{\begin{array}{l}
P_{N}=\frac{v_{\text {max }}}{3600 \eta_{T}} \times\left(m \times g \times f+\frac{C_{d} \times A \times v_{\text {max }}^{2}}{21.15}\right) \\
P_{N 1}=\frac{v}{3600 \eta_{T}} \times\left(m \times g \times f \cos \alpha_{\text {max }}+m \times g \times \sin \alpha_{\text {max }}+\frac{C_{d} \times A \times v^{2}}{21.15}\right) \\
P_{N 2}=\frac{1}{3600 \cdot t_{m} \cdot \eta_{t}}\left(\delta \cdot m \cdot \frac{v_{m}{ }^{2}}{2}+m \cdot g \cdot f \frac{v_{m}}{1.5} \cdot t_{m}+\frac{C_{d} \cdot A \cdot v_{m}^{3}}{21.15 \cdot 2.5} \cdot t_{m}\right)
\end{array}\right.
$$

Among them, $\mathrm{P}_{\mathrm{N}}-$ motor rating power; $\eta_{\mathrm{T}} \longrightarrow$ transmission coefficient of efficiency; $\mathrm{m}$ — vehicle weight, $\mathrm{kg} ; \mathrm{f}-$ Rolling resistance coefficient; $\mathrm{C}_{\mathrm{d}}$-Drag coefficient; $\mathrm{A} \longrightarrow$ vehicle frontal area; $\mathrm{v}_{\max } \longrightarrow$ maximum speed of vehicle, $\mathrm{km} / \mathrm{h}$ 。

Table 1. The Main Simulation Parameters

\begin{tabular}{|c|c|c|}
\hline $\begin{array}{c}\text { full load vehicle quality } \\
(\mathrm{kg})\end{array}$ & maximum speed $(\mathrm{km} / \mathrm{h})$ & $\begin{array}{c}\text { full load centroid height } \\
(\mathrm{mm})\end{array}$ \\
\hline 1580 & 120 & 500 \\
\hline $\begin{array}{c}\text { the centroid to the rear axle } \\
(\mathrm{mm})\end{array}$ & $\begin{array}{c}\text { the centroid to the front axle } \\
(\mathrm{mm})\end{array}$ & frontal area $\left(\mathrm{m}^{2}\right)$ \\
\hline 1200 & 1470 & 1.97 \\
\hline $\begin{array}{c}\text { lithium battery capacity } \\
(\text { Ah) }\end{array}$ & rolling resistance coefficient & wheel radius $(\mathrm{mm})$ \\
\hline 100 & 0.009 & 289 \\
\hline
\end{tabular}

The CENS lithium battery CBP2450 is used in the energy storage system, the 13 section is connected in series to a group, the 2 groups in parallel, the performance index and characteristic curve are shown in Figure 1 and Table 2; The super-capacitor performance indicators of American MAXWELL BMOD0165 are shown in Table 3.
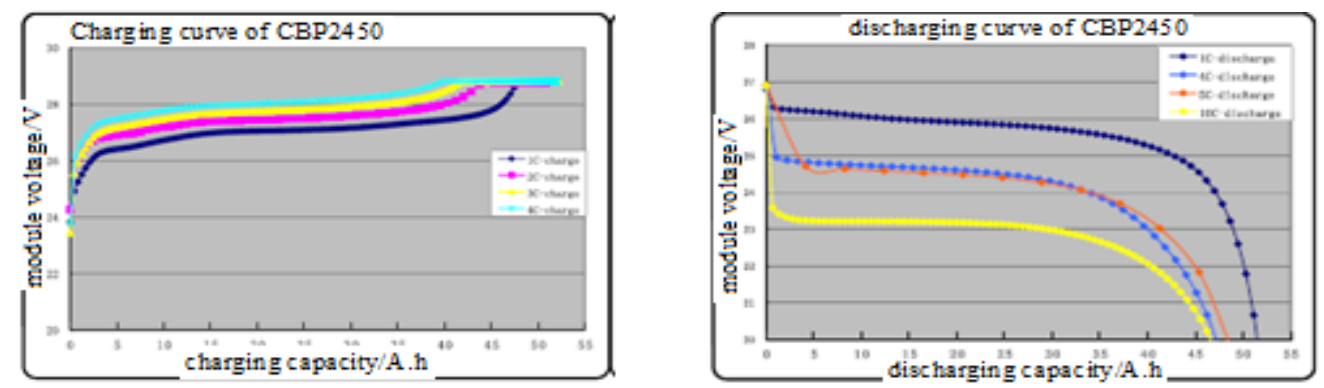

Figure 1. The Charging and Discharging Characteristic Curves of CBP2450

Table 2. Lithium Battery CBP2450 Monomer Performance Indexes

\begin{tabular}{|c|c|c|c|c|c|}
\hline \multicolumn{2}{|c|}{ nominal voltage $(\mathrm{V})$} & \multicolumn{2}{|c|}{$\operatorname{size}\left(\mathrm{m}^{3}\right)$} & \multicolumn{2}{|c|}{$\begin{array}{l}\text { mass specific power } \\
(\mathrm{W} / \mathrm{Kg})\end{array}$} \\
\hline \multicolumn{2}{|c|}{25.6} & \multicolumn{2}{|c|}{$355 * 318 * 146$} & \multicolumn{2}{|c|}{1000} \\
\hline \multicolumn{2}{|c|}{ nominal capacity (Ah) } & \multicolumn{2}{|c|}{ weight（Kg） } & \multicolumn{2}{|c|}{ internal resistance $(\mathrm{m} \Omega)$} \\
\hline \multicolumn{2}{|c|}{50} & \multicolumn{2}{|c|}{19} & \multicolumn{2}{|c|}{7} \\
\hline \multicolumn{3}{|c|}{ Discharge at $20^{\circ} \mathrm{C}$} & & \multicolumn{2}{|c|}{ charge at $20^{\circ} \mathrm{C}$} \\
\hline $\begin{array}{l}\text { standard } \\
\text { discharge }\end{array}$ & $\begin{array}{l}\text { maximum } \\
\text { discharge }\end{array}$ & cut-off voltage & $\begin{array}{l}\text { charging } \\
\text { voltage }\end{array}$ & $\begin{array}{l}\text { maximum } \\
\text { charge }\end{array}$ & charging time \\
\hline
\end{tabular}




\begin{tabular}{|l|l|l|l|l|l|}
\hline $50 \mathrm{~A}$ & $500(30 \mathrm{~S})$ & $20 \mathrm{~V}$ & $29 \mathrm{~V}$ & $300 \mathrm{~A}(30 \mathrm{~S})$ & $2 \mathrm{~h}$ \\
\hline
\end{tabular}

Table 3. Super-capacitor BMOD0165 Performance Indicators

\begin{tabular}{|c|c|c|}
\hline rated voltage & peak voltage & nominal capacity \\
\hline $48 \mathrm{~V}$ & $51 \mathrm{~V}$ & $165 \mathrm{~F}$ \\
\hline maximal peak current & operating temperature range & nominal quality \\
\hline 1900A & $-40 \sim 65^{\circ} \mathrm{C}$ & $13.5 \mathrm{Kg}$ \\
\hline maximum stored energy & nominal size $(\mathrm{mm})$ & combination form \\
\hline 52.8w.h & $418^{*} 194^{*} 179$ & 7 series of monomer \\
\hline
\end{tabular}

\section{Topology Structure Analysis}

The HESS with two energy storage elements and one load has seven possible configurations, as shown in Figure 1. Choosing the most appropriate configuration depends on the application and power demand. The simplest choice is shown in Figure 1(a) adopted in this paper, where the u-cap, battery, and load are directly connected in parallel. This connection is simple, the power consumption is relatively small; in this strategy the logic gate is used to control the battery and super-capacitor, eliminating the loss of DCDC controller power, reducing the control instability.

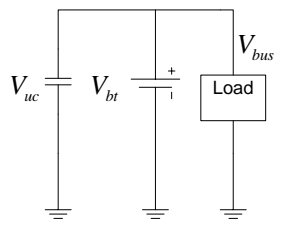

(a)

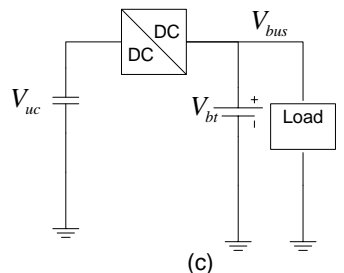

(c)

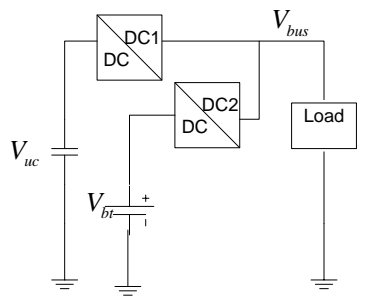

(e)

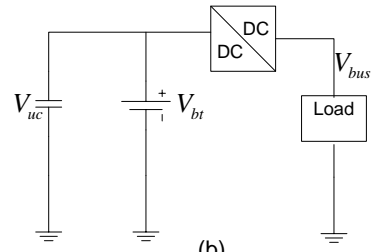

(b)

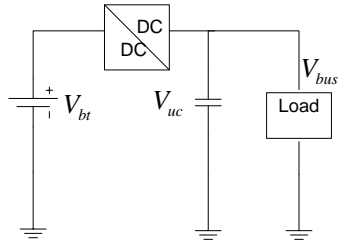

(d)

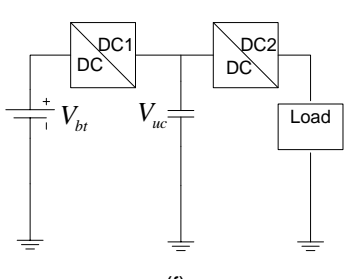

(f)

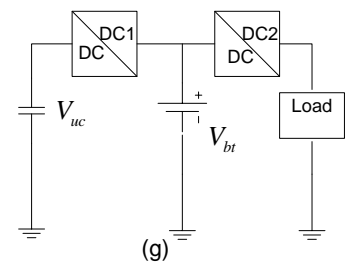

Figure 1. Seven Possible Configurations for a Two-source and Single-load HESS 


\section{Build the Model based on Longitudinal Dynamics Characteristics}

According to the running equation of the vehicle given by

$$
\frac{T_{t q} i_{g} i_{0} \eta_{t}}{r}=G f+\frac{C_{D} A u_{a}^{2}}{21.15}+G \sin \alpha+\delta m \frac{d u}{d t}
$$

Take isolated body from the various parts of the vehicle, and take the driven wheel, the driving wheel and the rest of the car to analyze the force.

(1)The force analysis of driven wheels during acceleration

Figure 3 is the free body diagram of driven wheel during acceleration. $\mathrm{m} 1$ is the quality of the driven wheel, $I_{w l}$ is the driven wheels' moment of inertia; W1 is the load on the driven wheel, $F_{z 1}$ is the force to the normal reaction force of driven wheel, FP1 is the thrust from driven shaft to driven wheel,FX1 is ground tangential reaction,Tf1 is driven wheel rolling

resistance moment, $m_{1} d u / d t$ is driven wheel translational inertia force, $I_{w 1} d w / d t$ is inertia moment of couple of driven wheel.

According to the force equilibrium condition, it can push out that the thrust from driven shaft to driven wheel is

$$
F_{t}=F_{f 1}+\left(m_{1}+\frac{I_{w 1}}{r^{2}}\right) \frac{d u}{d t}
$$

(2)The force analysis of driving wheels during acceleration

Figure 4 is the free body diagram of driving wheel during acceleration. $m_{2}$ is the quality of the driving wheel, $I_{w 2}$ is the driving wheels' moment of inertia; $W_{2}$ is the load on the driving wheel, $F_{Z 2}$ is the face to the normal reaction force of driving wheel, $F_{P 2}$ is the resistance of the drive shaft to the drive wheels, $F_{X 2}$ is ground tangential reaction, $T_{f 2}$ is driving wheel rolling resistance moment, $m_{2} \frac{d u}{d t}$ is driving wheel translational inertia force, $I_{w 2} \frac{d w}{d t}$ is inertia moment of couple of driving wheel. $T_{t}^{\prime}$ is half axle acting on the driving wheel torque, similarly available, the thrust of driving wheel is

$$
F_{t}=F_{P 2}+F_{f 2}+\left[m_{2}+\frac{I_{w 2}}{r^{2}}+\frac{I_{f} i_{g}^{2} i_{0}^{2} \eta_{T}}{r^{2}}\right] \frac{d u}{d t}
$$

According to the relationship of the wheel force and demand power as well as the characteristics of the main parts of reverse building the electric vehicle model, as shown in Figure 7 Braking energy feedback is mainly from driving wheel, the control strategy to test the power of driving wheel, the flow chart as shown in the figure below. $P_{\text {qreq }}$ is the power of driving wheel, $P_{\text {Req }}$ is the required power of the vehicle, $P_{\text {Min }}$ is the minimum power which is provided by the battery, $P_{F s a p}$ is that the maximum power stored in the capacitor; $V_{\text {Scap }}$ is the actual voltage of capacitor; $V_{\mathrm{Re} q}$ is the minimum voltage of the capacitor; $P_{c h}$ is the capacitor charging power given by the battery. The vehicle model construction based on the analysis of longitudinal dynamics is shown in Figure 5. 


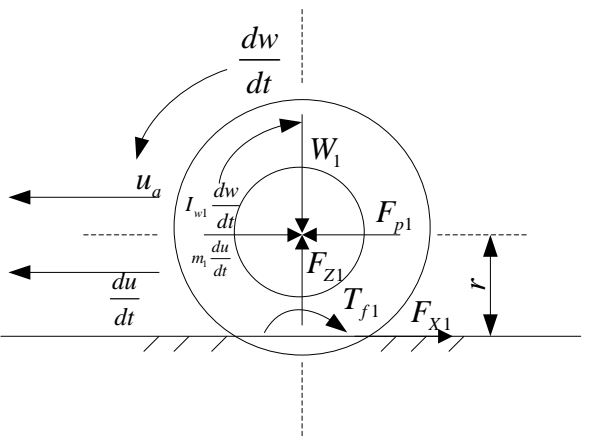

Figure 3. Free Body Diagram of Driven Wheel during Acceleration

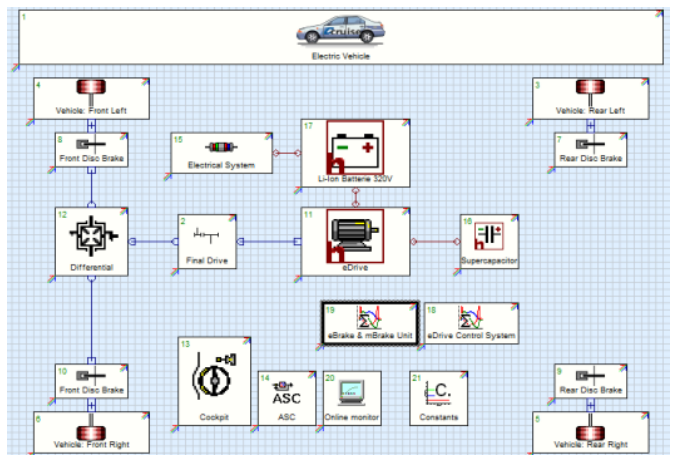

Figure 5. Model Construction

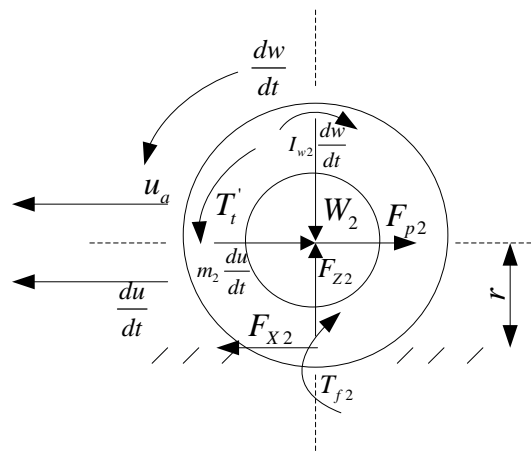

Figure 4. Free Body Diagram of Driving Wheel during Acceleration

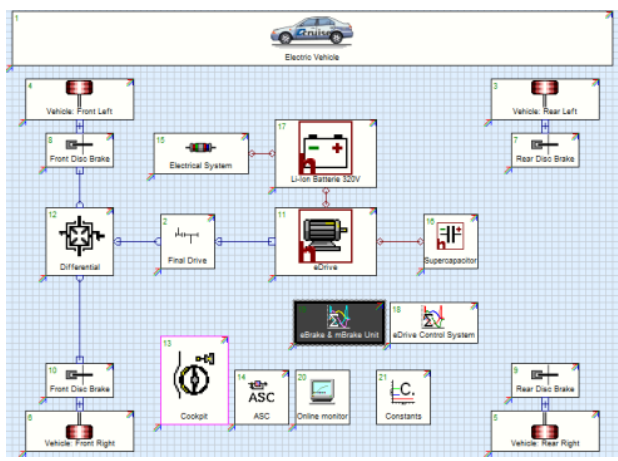

Figure 6. The Vehicle Mode after the Strategy Established

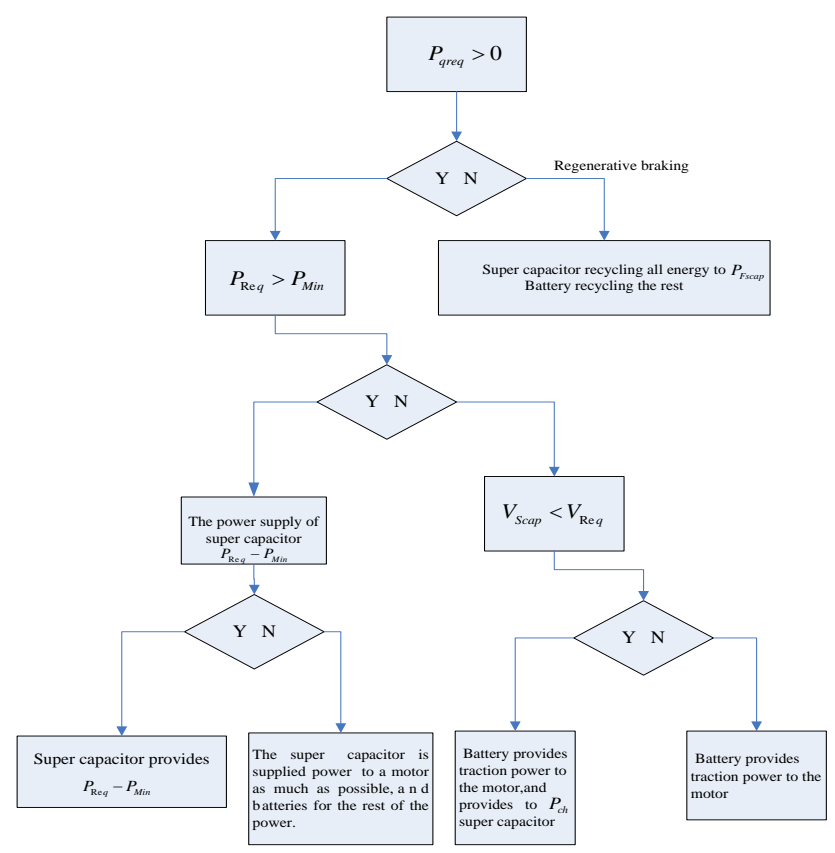

Figure 7. The Flow Chart of Control Strategy 
According to the flow chart of the control strategy in Figure 7, establish "eBrake\& mBrake Unit" in CRUISE, connect the super-capacitors and batteries with data bus connection, set" Switch" logic gate, as shown in black module of Figure 6.

In the standard road condition NEDC cycle, the SOC of battery, endurance mileage、 fuel consumption per hundred kilometers and full climbing performance are researched in the simulation study, the traffic parameters are as shown in Table 3.

Table 3. NEDC Traffic Parameters

\begin{tabular}{|c|c|c|}
\hline time $(\mathrm{s})$ & distance $(\mathrm{km})$ & maximum speed $(\mathrm{km} / \mathrm{h})$ \\
\hline 1184 & 10.93 & 120 \\
\hline maximum deceleration $(\mathrm{m} / \mathrm{s} 2)$ & average acceleration $(\mathrm{m} / \mathrm{s} 2)$ & average deceleration $(\mathrm{m} / \mathrm{s} 2)$ \\
\hline-1.39 & 0.54 & -0.79 \\
\hline average speed $(\mathrm{km} / \mathrm{h})$ & maximum acceleration $(\mathrm{km} / \mathrm{h})$ & idle time $(\mathrm{s})$ \\
\hline 33.21 & 1.06 & 298 \\
\hline
\end{tabular}

\section{The Simulation Results Analysis}

Simulation study based on the construction of models and control strategy, Figure 7 and Figure 8 is a single NEDC conditions of motor power distribution curve and the change of SOC from the initial value of $95 \%$.

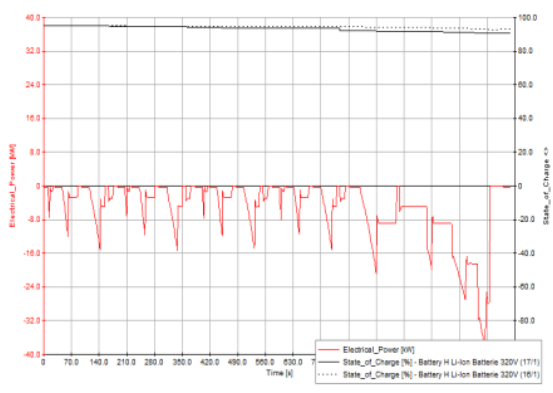

Figure 7. Motor Power and Battery SOC Changes on NEDC Road Cycle

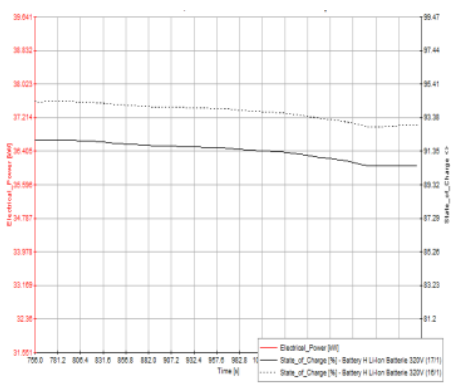

Figure 8. In View of the Figure 7 SOC of Partial Enlargement

As seen from Figure 8, the SOC in improvement strategy represented by the dotted line is $92.8968 \%$, represented by the solid line the SOC of the original vehicle model is $90.4514 \%$, the SOC value increased by $2.71 \%$.

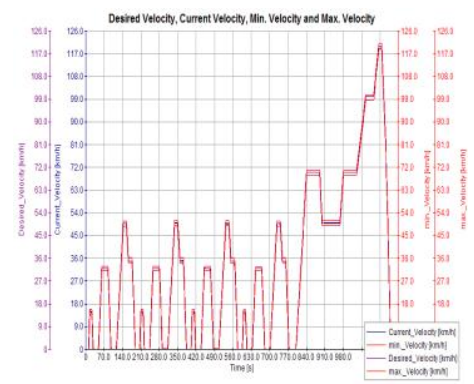

Figure 9. Comparison Figure of the Actual Speed and Working Referenced Speed

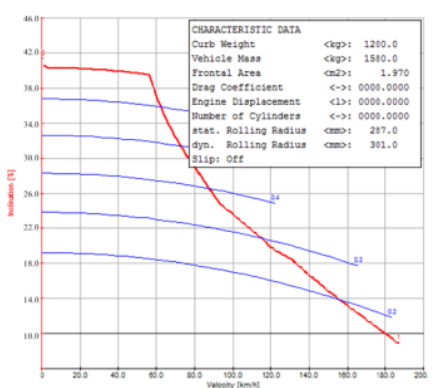

Figure 10. Analysis on Full Load Climbing Performance 
As seen from Figure 9, the design of composite energy management system can guarantee the power demand of the vehicle effectively,the difference between the actual speed and the reference velocity on the working condition is controlled within 5\%, the power output of the vehicle is ensured and the expect requires of control strategies are achieved.

In the full load climbing performance experiments, the climbing performance is added in the Project-Task Folder, the maximum climbable gradient is $39.4 \%$, the climbing performance has been greatly improved as shown in Figure 10. The SOC of the battery in the simulation experiment changes smoothly ,avoiding the excessive charging and discharging frequently in the lithium battery, which has played an important role in protecting the battery.In addition, from the experimental results we can know that hundreds kilometers energy consumption is from $12 \mathrm{Kw}$ to $7.5 \mathrm{KWH}$, power consumption is reduced by $37.5 \%$; SOC has decreased from $95 \%$ to $90.3 \%$; the mileage of the traditional electric vehicle is $15.302 \mathrm{~km}$, in the improved control strategy the total endurance mileage has increase nearly $40 \%$ of the distance.

\section{Conclusion}

Hafei Saibao electric vehicle is taken as a research object, the super- capacitor is added as energy storage in this paper. On the basis of the experimental data, we use the CruiseMATLAB simulation and the reasonable configuration scheme of power system is determined, and the basis for subsequent vehicle development is also provided; in the process of running, the SOC of the battery changes smoothly, the endurance mileage of Vehicle has increased by about $40 \%$, the best match between vehicle and energy storage system is achieved. The effective basis and methods are provided by this method for other forms of composite energy combination analysis of pure electric vehicles, also for electric vehicle energy problems such as limit on-board energy and short endurance mileage.

\section{Acknowledgements}

This work is supported by the Natural Science Foundation of China (Grant No.51275137) and Heilongjiang Natural Science Foundation (Grant No.E201302). The authors express their gratitude for valuable suggestions and advice from the anonymous reviewers.

\section{References}

[1]. R. Carter, A. Cruden, P. J. Hall and A. S. Zaher, "An improved lead acid battery pack model for use in power simulations of electric vehicles," IEEE Trans. Energy Convers., vol. 27, no. 1, (2012) March, pp. 21-28.

[2]. G. Qiuming, L. Yaoyu and P. Zhongren, "Trip based optimal power management of plug-in hybrid electric vehicle with advanced traffic modelling", SAE International Journal of Engines (S1946-3936), vol. 1, no. 1, (2009), pp. 861-872.

[3]. Adhikari, "An Online Power-Balancing Strategy for a Parallel Hybrid Electric Vehicle Assisted by an Integrated Starter Generator", Ieee Transactions on Vehicular Technology, (2010), pp. 2689-2699.

[4]. Hegazy, "PSO algorithm-based optimal power flow control of fuel cell/supercapacitor and fuel cell/battery hybrid electric vehicles", the International Journal for Computation and Mathematics in Electrical and Electronic Engineering, (2013), pp. 86-107.

[5]. Millo, "Development of an optimal strategy for the energy management of a range-extended electric vehicle with additional noise, vibration and harshness constraints", Proceedings of the Institution of Mechanical Engineers Part D-Journal of Automobile Engineering, (2013), pp. 4-16.

[6]. Y. L. Murphey, J. Park, L. Kiliaris, M. L. Kuang, M A. Masrur, A. M. Phillips and Q. Wang, "Intelligent Hybrid Vehicle Power Control-Part II: Online Intelligent Energy Management”, Vehicular Technology, vol. 62, no. 1, (2013), pp. 69-79.

[7]. H. Khayyam, "Stochastic Models of Road Geometry and Wind Condition for Vehicle Energy Management and Control", Vehicular Technology, vol. 62, no. 1, (2013), pp. 61-68. 
[8]. D. F. Opila, X. Wang, R. McGee, R. Gillespie, C. Brent, J. A. Grizzle and W. Jessy, "An Energy Management Controller to Optimally Trade Off Fuel Economy and Drivability for Hybrid Vehicles", Control Systems Technology, vol. 20, no. 6, (2012), pp. 1490 - 1505.

[9]. S. G. Li, S. A. Sharkh, F. C. Walsh and C.-N. N. Zhang, "Energy and Battery Management of a Plug-In Series Hybrid Electric Vehicle Using Fuzzy Logic", Vehicular Technology, vol. 60, no. 8, (2011), pp. 35713585 .

[10].A. Tani, M. B. Camara, B. Dakyo and Y. Azzouz, "DC/DC and DC/AC Converters Control for Hybrid Electric Vehicles Energy Management-Ultra capacitors and Fuel Cell”, Industrial Informatics, vol. 9, no. 2, (2013), pp. 686-696.

[11].H. Borhan, A. Vahidi, A. M. Phillips, M. L. Kuang, I. V. Kolmanovsky and S. D. Cairano, "MPC-Based Energy Management of a Power-Split Hybrid Electric Vehicle”, Control Systems Technology, vol. 20, no. 3, (2012), pp. 593-603.

[12].C. Zhang and A. Vahidi, "Route Preview in Energy Management of Plug-in Hybrid Vehicles", Control Systems Technology, vol. 20, no. 2, (2012), pp. 546-553.

[13].S. Kelouwani, N. Henao, K. Agbossou, Y. Dubé and L. Boulon, "Two-Layer Energy Management Architecture for a Fuel Cell HEV Using Road Trip Information”, Vehicular Technology, vol. 61, no. 9, (2012), pp. 3851-3864.

[14].Y. Haifang, "Research on parameter matching and control strategy of hybrid energy storage system for HEV”, Harbin: Harbin Institute of Technolog, (2010).

[15].W. Jian, C. Naxin, Z. Chenghui, et al., "PSO algorithm-based optimization of plug-in hybrid electric vehicle energy management strategy", The 8th World Congress on Intelligent Control and Automation, (2010), pp. $3997-4002$.

[16].X. Meng and N. Langlois, "Optimized fuzzy logic control strategy of hybrid vehicles using ADVISOR," Computer, Mechatronics, Control and Electronic Engineering (CMCE), 2010 International Conference on, vol. 4, (2010) August 24-26, pp. 444-447. 